\title{
On the determination of an unknown source in the parabolic equation
}

\author{
Pabyrivska N., Pabyrivskyy V. \\ Lviv Polytechnic National University \\ 12 S. Bandera str., 79013, Lviv, Ukraine
}

(Received 18 July 2017)

\begin{abstract}
The paper establishes existence and unique conditions for an inverse problem with an unknown source. The unknown source is a polynomial for a spatial variable with unknown coefficients depending on time.
\end{abstract}

Keywords: inverse problem, Green's function, Volterra integral equations, unknown source.

2000 MSC: $35 \mathrm{R} 30$

UDC: 517.95

DOI: $10.23939 / \mathrm{mmc} 2017.02 .171$

\section{Introduction}

The theory of inverse problems for parabolic equations began to develop intensively in the mid-seventies of the past century. Inverse problems have become widely used in various fields of science and technology, since they provide an opportunity to determine the physical properties and characteristics of processes diverse by nature by mathematical calculations without conducting field experiments.

The inverse problems of identification of the coefficients for parabolic equation were considered in various formulations in numerous works of national and foreign mathematicians. The problem of determination of the unknown free term is the simplest among coefficient inverse problems. Particularly in this direction the following results were obtained. In paper [1] a free term of the heat equation was being looked up as a product of two unknown functions $f(t) g(x)$. In [2] the unknown source has the form $f_{1}(x) g_{1}(t)+f_{2}(t) g_{2}(x)$, where $f_{1}(x), f_{2}(t)$ have to be identified. For this problem, the local conditions of existence and uniqueness of the solution are set. This problem was analyzed in paper [3], for the case of integrated overdetermination conditions, and contained numerous examples of its implementation. Paper [4] also shows the numerical solution of inverse problems of simultaneous determination of timedependent coefficients of the younger members and the source of the parabolic equation. In [5] the inverse problem with the three unknown functions, dependent on various arguments, which stand on the right side of the weakly nonlinear ultra parabolical equation with mixed boundary conditions and integral conditions was illustrated. The conditions of existence and uniqueness at some finite time interval of the generalized solution of the considered problem were set, the components of which belong to Sobolev spaces. Paper [6] is dedicated to finding sources in a parabolic integro-differential equation in the form $\chi(t) \omega(x), \chi\left(x_{n}\right) \omega(\bar{x}, t)$ and $\sum_{j=1}^{n} \omega_{j} \chi_{j}(x, t)$, where $\chi, \chi_{j}$ are the specified functions.

\section{Formulating the problem}

A large number of technological processes in metallurgy occur at elevated temperatures. In such cases, it is often impossible to control the temperature during experiments. This happens when the heated object is of small geometric dimensions, such as a thin wire or when the heating takes place in an environment that is not accessible for installing temperature sensors. In recent years, in practice, new high-speed methods of heat treatment of metals have been widely used, the temperature distribution 
here can be controlled using a mathematical model, using solutions for inverse problems. This raises the problem of the existence and uniqueness of the solution for such problems.

Let's have a thin rod of length $l$. Because of $u(x, t)$ we denote its temperature at the coordinate point $x$ at the time $t$. It is necessary to organize such a process in a way that certain areas of the rod $\left(x=0, x=l_{1}, x=l_{2}, \ldots, x=l\right)$ have predetermined time-dependent temperature regimes. This can be achieved due to the thermal effects of internal heat sources, that is, solving the problem of controlling the source in the heat equation. In fact, we need to investigate the inverse problem for the heat equation with an unknown free member, which depends on the spatial variable $x$ and time $t$.

The question of the complete determination of the source (the definition of a free member, which depends on spatial and time variables) remains open today. A certain solution to complete definition of an unknown member of the parabolic equation is a polynomial approximation for its spatial variables with unknown coefficients that depend on time. This task of identification of the source of the polynomial is developed in this study. The approach to a complete determination of the unknown coefficients parabolic equation was tested in $[7,8]$, where the conditions of existence and uniqueness of the solution of the problem of identification of the major coefficient of the linear and quadratic functions of a spatial variable with unknown coefficients depending on the time variable were found.

\section{Mathematical model}

In the domain $\Omega=\{(x, t): 0<x<l, 0<t<T\}$ consider the parabolic equation

$$
u_{t}=u_{x x}+\sum_{j=0}^{n} x^{j} f_{j}(t)
$$

with unknown coefficients $f_{j}(t), j=\overline{0, n}$, with the initial condition

$$
u(x, 0)=\varphi(x), \quad x \in[0, l]
$$

the boundary conditions and the overdetermination conditions

$$
\begin{gathered}
u_{x}(0, t)=\mu_{1}(t), \quad u_{x}(l, t)=\mu_{2}(t), \\
u(0, t)=\nu_{1}(t), \quad u(l, t)=\nu_{2}(t), \\
u\left(l_{i}, t\right)=\nu_{i+2}(t), \quad l_{i} \in(0, l), \quad l_{i}<l_{i+1}, \quad i=\overline{1, n-1}, \quad t \in[0, T] .
\end{gathered}
$$

The solution of the problem (1)-(5) are the functions $\left(u(x, t), f_{i}(t)\right) \in C^{2,1}(\Omega) \cap C^{1,0}(\bar{\Omega}) \times$ $(C[0, T])^{n+1}, i=\overline{0, n}$, that satisfy conditions (1)-(5).

\section{Existence and uniqueness of the solution for the problem}

Assuming that the output data possess the required smoothness and the conditions for their compliance, we reduce problem (1)-(5) to the system of equations for unknown functions $f_{i}(t), i=\overline{0, n}$. For this reason, let set $x=0, l, l_{1}, \ldots, l_{n-1}$, in the equation (1). In result we get the following correlations

$$
\begin{aligned}
\nu_{1}^{\prime}(t) & =u_{x x}(0, t)+f_{0}(t), \\
\nu_{2}^{\prime}(t) & =u_{x x}(l, t)+\sum_{j=0}^{n} l^{j} f_{j}(t), \\
\nu_{i+2}^{\prime}(t) & =u_{x x}\left(l_{i}, t\right)+\sum_{j=0}^{n} l_{i}^{j} f_{j}(t), \quad i=\overline{1, n-1},
\end{aligned}
$$

Mathematical Modeling and Computing, Vol.4, No. 2, pp.171-176 (2017) 
or

$$
\begin{aligned}
f_{0}(t) & =\nu_{1}^{\prime}(t)-u_{x x}(0, t), \\
\sum_{j=0}^{n} l^{j} f_{j}(t) & =\nu_{21}^{\prime}(t)-u_{x x}(l, t), \\
\sum_{j=0}^{n} l_{i}^{j} f_{j}(t) & =\nu_{i+2}^{\prime}(t)-u_{x x}\left(l_{i}, t\right), \quad i=\overline{1, n-1},
\end{aligned}
$$

where $u(x, t)$ is the solution of the direct problem (1)-(3), which has the form

$$
\begin{aligned}
u(x, t)= & \int_{0}^{h} \varphi(\xi) G_{2}(x, t, \xi, 0) d \xi-\int_{0}^{t} \mu_{1}(\tau) a(\tau) G_{2}(x, t, 0, \tau) d \tau+\int_{0}^{t} \mu_{2}(\tau) a(\tau) G_{2}(x, t, h, \tau) d \tau \\
& +\int_{0}^{t} \int_{0}^{h} \sum_{j=0}^{n} \xi^{j} f_{j}(\tau) G_{2}(x, t, \xi, \tau) d \xi d \tau,
\end{aligned}
$$

$G_{2}(x, t, \xi, \tau)$ is Green function of the second kind, which has the form

$$
\begin{gathered}
G_{2}(x, t, \xi, \tau)=\frac{1}{2 \sqrt{\pi}(\theta(t)-\theta(\tau))} \sum_{n=-\infty}^{\infty}\left(\exp \left(-\frac{(x-\xi+2 n h)^{2}}{4(\theta(t)-\theta(\tau))}\right)+\exp \left(-\frac{(x+\xi+2 n h)^{2}}{4(\theta(t)-\theta(\tau))}\right)\right) \\
\theta(t)=\int_{0}^{t} a(\tau) d \tau .
\end{gathered}
$$

Let's take the second derivative with the respect to $x$ :

$$
\begin{aligned}
u_{x x}(x, t)= & \int_{0}^{h} \varphi^{\prime \prime}(\xi) G_{2}(x, t, \xi, 0) d \xi-\int_{0}^{t} \mu_{1}^{\prime}(\tau) G_{2}(x, t, 0, \tau) d \tau+\int_{0}^{t} \mu_{2}(\tau) G_{2}(x, t, h, \tau) d \tau \\
& +\int_{0}^{t} \int_{0}^{h} \sum_{j=1}^{n} j \xi^{j-1} f_{j}(\tau) G_{2 \xi}(x, t, \xi, \tau) d \xi d \tau .
\end{aligned}
$$

Let's show that the system (6) can be reduced to a system of Volterra integral equations of the second kind

$$
f_{i}(t)=F_{i}(t)+\sum_{j=0}^{n} P_{i j}(t) u_{x x}\left(l_{j}, t\right), \quad i=\overline{0, n},
$$

where $F_{i}(t), P_{i j}(t), i, j=\overline{0, n}$ are known functions, determined through input data, $l_{0}=0, l_{n}=l$.

It's enough to show that the determinant of the system (6)

$$
\Delta=\left|\begin{array}{ccccc}
1 & 0 & 0 & \ldots & 0 \\
1 & l & l^{2} & \ldots & l^{n} \\
1 & l_{1} & l_{1}^{2} & \ldots & l_{1}^{n} \\
\ldots & \ldots & \ldots & \ldots & \ldots \\
1 & l_{n-1} & l_{n-1}^{2} & \ldots & l_{n-1}^{n}
\end{array}\right|
$$

is nonzero. We will open this determinant by the first line and perform elementary transformations

$$
\Delta=\left|\begin{array}{cccc}
l & l^{2} & \ldots & l^{n} \\
l_{1} & l_{1}^{2} & \ldots & l_{1}^{n} \\
\ldots & \ldots & \ldots & \ldots \\
l_{n-1} & l_{n-1}^{2} & \ldots & l_{n-1}^{n}
\end{array}\right|=l \cdot l_{1} \cdot \ldots \cdot l_{n-1} \cdot\left|\begin{array}{cccc}
1 & l & \ldots & l^{n-1} \\
1 & l_{1} & \ldots & l_{1}^{n-1} \\
\ldots & \ldots & \ldots & \ldots \\
1 & l_{n-1} & \ldots & l_{n-1}^{n-1}
\end{array}\right|
$$

Mathematical Modeling and Computing, Vol.4, No. 2, pp.171-176 (2017) 
The received determinant is Vandermonde determinant, that's why $\Delta=l \cdot l_{1} \cdot \ldots \cdot l_{n-1}$. $\prod_{1 \leqslant k<m \leqslant n}\left(l_{m}-l_{k}\right)$. Since $l_{m} \neq l_{k}$ when $m \neq k$, then $\Delta \neq 0$. Then the system of equations $(6)$ can be reduced to the form (8).

Using the theory of Volterra integral equations of the second kind, it can be stated that the solution for the system of equations (8) exists and it is unique only if the following conditions are satisfied: (A) $\nu_{i}(t), \mu_{j}(t) \in C^{2}[0, T], i=\overline{1, n+1}, j=1,2, \varphi(x) \in C^{2}[0, h]$.

Based on the equivalence of the system of equations (8) and the problem (1)-(5), we conclude

Theorem 1. The problem (1)-(5) has a unique solution if the conditions of smoothness $(A)$ and harmonization $\varphi^{\prime}(0)=\mu_{1}(0), \varphi^{\prime}(l)=\mu_{2}(0), \varphi\left(l_{i}\right)=\nu_{i+1}, i=\overline{0, n}$, are satisfied.

Using the method proposed for solving previous problems, we can establish the existence and uniqueness of the solution for the inverse problem of determining unknown source of the equation (1) with the initial condition (2), boundary conditions and overdetermination conditions (3), (4) and integral conditions

$$
\int_{0}^{l} x^{i} u(x, t) d x=\chi_{i}(t), \quad i=\overline{0, n-2}, \quad t \in[0, T] .
$$

The above problem is reduced to a system of Volterra equations of the second kind as follows. Let set $x=0, l$ in equation (1). In result we get the following correlations

$$
\begin{aligned}
& \nu_{0}^{\prime}(t)=u_{x x}(0, t)+f_{0}(t), \\
& \nu_{1}^{\prime}(t)=u_{x x}(l, t)+\sum_{j=0}^{n} l^{j} f_{j}(t) .
\end{aligned}
$$

Having multiplied (1) to $x^{j}, j=\overline{0, n-2}$ and taken the integral over $x$ from 0 to $l$, we will get

$$
\begin{aligned}
& \chi_{0}^{\prime}(t)=\mu_{2}(t)-\mu_{1}(t)+\sum_{i=0}^{n} \frac{l^{i+1}}{i+1} f_{i}(t), \\
& \chi_{1}^{\prime}(t)=l \mu_{2}(t)-\nu_{2}(t)+\nu_{1}(t)+\sum_{i=0}^{n} \frac{l^{i+2}}{i+2} f_{i}(t), \\
& \chi_{j}^{\prime}(t)=l^{j} \mu_{2}(t)-j l^{j-1} \nu_{2}(t)+j(j-1) \chi_{j-2}(t)+\sum_{i=0}^{n} \frac{l^{i+j+2}}{i+j+2} f_{i}(t), \quad j=\overline{2, n-2} .
\end{aligned}
$$

The determinant of the system (10), (11) is

$$
\Delta=\left|\begin{array}{ccccc}
1 & 0 & 0 & \ldots & 0 \\
1 & l & l^{2} & \ldots & l^{n} \\
l & \frac{l^{2}}{2} & \frac{l^{3}}{3} & \ldots & \frac{l^{n+1}}{n+1} \\
\ldots & \ldots & \ldots & \ldots & \ldots \\
\frac{l^{n-1}}{n-1} & \frac{l^{n}}{n} & \frac{l^{n+1}}{n+1} & \ldots & \frac{l^{2 n-1}}{2 n-1}
\end{array}\right| .
$$

By the principle of mathematical induction, it can be shown, that $\Delta=(-1)^{2 n+1} l^{n^{2}} / p_{2 n-1} \neq 0$, where $p_{2 n-1}$ is product of numbers from 2 to $2 n-1$. The system $(10),(11)$ is reduced to the systems of Volterra of the second kind.

$$
f_{i}(t)=R_{i}(t)+\sum_{j=0}^{n} Q_{i j}(t) u_{x x}\left(l_{j}, t\right), \quad i=\overline{0, n}
$$

$R_{i}(t), Q_{i j}(t), i, j=\overline{0, n}$ are continuous functions, defined through output data. 
Based on the theory of Volterra equations of the second kind, the existence and uniqueness of the solution for the system (12), and hence the problem (1)-(3), (9) sets

Theorem 2. The solution for the problem (1)-(3), (9) exists and is unique, if the following conditions are satisfied
1) $\nu_{i}(t), \mu_{i}(t), \chi_{j} \in C^{1}[0, T], j=\overline{0, n-2}, i=1,2, \varphi(x) \in C^{2}[0, h]$;
2) $\varphi^{\prime}(0)=\mu_{1}(0), \varphi^{\prime}(l)=\mu_{2}(0), \varphi(0)=\nu_{1}(0), \varphi(l)=\nu_{2}(0), \int_{0}^{l} x^{i} \varphi(x) d x=\chi_{i}(0), i=\overline{0, n-2}$.

Remark 1. Typically, the method of integral inequalities is used to solve the coefficient inverse problems for parabolic equations. There is no need to use this method for the above problems, as they are reduced to the Volterra integral equations of the second kind. However, having examined the conditions which we get with the method of integral inequalities and the results which we get in this work, we can say that they come to complete accordance.

\section{Conclusions}

The theorem of the existence and uniqueness of the solution of the inverse problem of determining the unknown source, which is a mathematical model of the thermal process in the rod with a predefined temperature regimes at its individual points, is proven by theorem of the Volterra integral equations of the second kind.

The conditions for the existence and uniqueness of the solution of the inverse problem of determining an unknown source with additional conditions in the form of thermal moments are established.

[1] Savateev E. On the problem of identification of a coefficient in a parabolic equation. Sibirsk. Mat. Zh. 36 (1), 177-185 (1995), (in Russian).

Savateev E. On the problem of identification of a coefficient in a parabolic equation. Siberian Mathematical Journal. 36 (1), 160-167 (1995).

[2] Ivanchov M. Inverse problem for the multidimensional heat equation with unknown source. Matematychni Studii. 16, 93-98 (2001).

[3] Dinh Nho Hao, Phan Xuan Thanh, Lesnic D., Ivanchov M. Determination of a source in the heat equation from integral observations. Journal of Computational and Applied Mathematics. 264, 82-98 (2014).

[4] Hussein M. S., Lesnic D. Simultaneous determination of time-dependent coefficients and heat source. International Journal for Computational Methods in Engineering Science and Mechanics. 17 (5-6), 401-411 (2016).

[5] ProtsakhN. Obernena zadacha dlya slabko nelinijnogo ul'traparabolichnogo rivnyannya z nevidomoyu pravoyu chasty'noyu. Ukr. Math. J. 66 (3), 333-348 (2014), (in Ukrainian).

Protsakh N. Inverse Problem for a Semilinear Ultraparabolic Equation with Unknown Right-Hand Side. Ukr. Math. J. 66 (3), 371-390 (2014).

[6] Kairi Kasemets, Jaan Janno. Reconstruction of a Source Term in a Parabolic Integro-Differential Equation from Final Data. Mathematical Modelling and Analysis. 16 (2), 199-219 (2011).

[7] Pabyrivska N., Vlasov V. Determination of leading coefficient in parabolic equation. Mathematical methods and physico-mechanical fields. 49 (3), 18-25 (2006), (in Ukrainian).

[8] Pabyrivska N., Varenyk O. Determination of a minor coefficient of a parabolic equation. Visnyk of the Lviv University. Series Mechanics and Mathematics. 64, 181-189 (2005), (in Ukrainian). 


\section{Про визначення невідомого джерела у параболічному рівнянні}

Пабирівська Н., Пабирівський В.

Національний університет «Львівсъка політехніка»

вул. С. Бандери, 12, 79013, Львів, Україна

Встановлено умови існування та єдиності розв'язку оберненої задачі з невідомим джерелом. Невідоме джерело має вигляд полінома за просторовою змінною з невідомими коефіцієнтами, що залежать від часу.

Ключові слова: обернена задача, функиіл Гріна, інтегральні рівняння Вольтерри, невідоме джерело.

2000 MSC: $35 R 30$

Удк: 517.95 